\title{
Análise do fluxo de água virtual: uma abordagem a partir da balança comercial de Mato Grosso do Sul
}

\author{
Analysis of the virtual water flow: an approach based on the trade balance of \\ Mato Grosso do Sul
}

\section{Analyse du flux d'eau virtuel: une approche basée sur la balance commerciale du Mato Grosso do Sul}

\section{Análisis del flujo de agua virtual: un enfoque a partir de la balanza comercial de Mato Grosso do Sul}

\author{
Adriana Kirchof de Brum ${ }^{1}$ \\ Daniel Massen Frainer ${ }^{2}$ \\ Celso Correia Souza ${ }^{3}$ \\ José Francisco dos Reis Neto ${ }^{3}$
}

Recebido em: 20/04/2017; revisado e aprovado em 20/12/2017; aceito em 27/12/2017

DOI: http://dx.doi.org/ 10.20435/inter.v0i0.1587

\begin{abstract}
Resumo: A alocação dos recursos hídricos tem despertado a atenção dos mais diversos segmentos da sociedade moderna. Geralmente, em regiões caracterizadas pela agropecuária, como é o caso do estado de Mato Grosso do Sul (MS), o uso da água no processo de produção se torna mais intensivo, de forma a refletir na utilização dos recursos naturais. A ideia de "água virtual" baseia-se no conceito de água embutida nos produtos, e tem despertado crescente interesse da comunidade nacional e internacional tendo em vista a necessidade de aprimorar a gestão dos recursos hídricos. Sendo assim, o objetivo principal deste artigo é analisar o saldo de água virtual decorrente do comércio internacional do Estado sul-mato-grossense e o resto do mundo, de forma a verificar o saldo superavitário ou deficitário em relação aos seus principais produtos comercializados no exterior. Para verificar se o balanço virtual de água é favorável ou desfavorável ao Estado, devem-se mensurar as relações de troca no comércio produto a produto utilizando-se a metodologia do cálculo da Pegada Hídrica proposta por Hoekstra et al. (2011) bem como dos indicadores de encadeamento para trás e para frente definidos pela matriz de insumo-produto a fim de entender o comportamento da demanda de água na economia do Estado. Os resultados apontam para um déficit no balanço das transações de água entre esse Estado e as demais economias com que comercializa seus produtos.
\end{abstract}

Palavras-chave: economia ambiental; Mato Grosso do Sul; água virtual.

Abstract: The allocation of water resources has attracted the attention of the most diverse segments of modern society. Generally, in regions characterized by agriculture, such as the state of Mato Grosso do Sul (MS), the use of water in the production process becomes more intensive, so as to reflect on the use of natural resources. The idea of "virtual water" is based on the concept of water embedded in the products, and has attracted growing interest from the national and international community in view of the need to improve the management of water resources. Therefore, the main objective of this article is to analyze the balance of virtual water resulting from the international trade of the South-Mato Grosso State and the rest of the world in order to verify the surplus or deficit balance in relation to its main products marketed abroad. In order to verify if the virtual water balance is favorable or unfavorable to the State, one should measure the exchange ratios in the product-to-product trade using the methodology of the calculation of the Water Footprint proposed by Hoekstra et al. (2011) as well as the backward and forward chaining indicators defined by the input-output matrix in order to understand the behavior of water demand in the state economy. The results point to a deficit in the balance of water transactions between this State and the other economies with which it markets its products.

Keywords: environmental economics; Mato Grosso do Sul; virtual water.

\footnotetext{
${ }^{1}$ Universidade Federal da Grande Dourados (UFGD), Dourados, Mato Grosso do Sul, Brasil.

${ }^{2}$ Universidade Estadual de Mato Grosso do Sul (UEMS), Ponta Porã, Mato Grosso do Sul, Brasil.

${ }^{3}$ Uniderp-Anhaguera, Campo Grande, Mato Grosso do Sul, Brasil.
} 
Résumé: L'allocation des ressources en eau a attiré l'attention des segments les plus divers de la société moderne. En général, dans les régions caractérisées par l'agriculture, comme l'État du Mato Grosso do Sul (MS), l'utilisation de l'eau dans le processus de production devient plus intensive afin de refléter l'utilisation des ressources naturelles. L'idée de «l'eau virtuelle» repose sur le concept d'eau intégrée dans les produits et suscite un intérêt croissant de la part de la communauté nationale et internationale face à la nécessité d'améliorer la gestion des ressources en eau. Ainsi, l'objectif principal de cet article est d'analyser l'équilibre de l'eau virtuelle en raison du commerce international du Mato Grosso du Sud Etat et le reste du monde afin de vérifier l'excédent ou le solde du déficit par rapport à ses principaux produits vendus à l'étranger. Pour vérifier que l'équilibre de l'eau virtuelle est favorable ou défavorable à l'Etat, devrait être la mesure des rapports d'échange dans le produit du commerce par produit en utilisant la méthode de calcul de l'empreinte sur l'eau proposée par Hoekstra et al. (2011), ainsi que la chaîne d'indicateurs amont et en aval définis par la matrice d'entrée-sortie afin de comprendre le comportement de la demande en eau dans l'économie de l'État. Les résultats indiquent un déficit dans l'équilibre des transactions de l'eau entre cet État et les autres économies avec lesquelles il commercialise ses produits.

Mots-clés: économie de l'environnement; Mato Grosso do Sul; l'eau virtuelle.

Resumen: La asignación de los recursos hídricos ha despertado la atención de los más diversos segmentos de la sociedad moderna. En general, en regiones caracterizadas por la agropecuaria, como es el caso del estado de Mato Grosso del Sur (MS), el uso del agua en el proceso de producción se vuelve más intensivo, para reflejar en la utilización de los recursos naturales. La idea de "agua virtual" se basa en el concepto de agua embutida en los productos, y ha despertado creciente interés de la comunidad nacional e internacional teniendo en cuenta la necesidad de mejorar la gestión de los recursos hídricos. Por lo tanto, el objetivo principal de este artículo es analizar el saldo de agua virtual resultante del comercio internacional del Estado sur-mato-grueso y el resto del mundo para verificar el saldo superavitario o deficitario en relación a sus principales productos comercializados en el exterior. Para verificar si el balance virtual de agua es favorable o desfavorable al Estado, se deben medir las relaciones de intercambio en el comercio producto a producto utilizando la metodología del cálculo de la Huella Hídrica propuesta por Hoekstra et al. (2011) y los indicadores de encadenamiento para trazar y hacia delante definidos por la matriz de insumo-producto a fin de entender el comportamiento de la demanda de agua en la economía del Estado. Los resultados apuntan a un déficit en el balance de las transacciones de agua entre ese Estado y las demás economías con que comercializa sus productos.

Palabras clave: economía del medio ambiente; Mato Grosso do Sul; agua virtual.

\section{INTRODUÇÃO}

$\mathrm{Na}$ atual conjuntura do mercado internacional de commodities, o Brasil desempenha importante papel como um dos maiores exportadores de soja, carne e açúcar. Entretanto, além das relações econômicas decorrentes do comércio desses produtos, destaca-se também outra questão, não menos relevante para a sustentabilidade produtiva: a disponibilidade de recursos hídricos e sua capacidade de atender à crescente demanda por alimentos.

O conceito dominante de desenvolvimento sustentável consiste em mensurar como o planeta pode proporcionar recursos suficientes para assegurar o bem-estar das pessoas nas mais diversas regiões e de maiores parcelas da sociedade.

Nesse particular, destaca-se a análise da capacidade de atendimento da demanda direta e indireta do uso da água doce, desafio esse que tem se demonstrado cada vez maior, haja vista a necessidade crescente de abastecimento nos centros urbanos, fortemente associado à degradação do meio ambiente.

Embora o planeta Terra seja constituído por 71\% de água, boa parte desse volume não é apropriado para o consumo direto. De acordo com a Food and Agriculture Organization of the United Nations (FAO, 2007), 1.400 milhões de $\mathrm{km}^{3}$ é o volume total de água disponível no mundo. Desse volume, 2,7\% representam a parcela de "água doce", que pode ser utilizada no consumo humano (beber, cozinhar, higiene), na agricultura e na indústria. Desse total de água doce, 0,26\% é considerado de fácil acesso (rios, lagos e represas), em que apenas 0,002\% é de água potável. 
Conforme o Banco Mundial (2014), os recursos hídricos do Brasil representam 12,8\% das reservas de água doce do mundo. No entanto a distribuição espacial deles encontra-se distribuída de forma desigual no território nacional. A maior concentração dos recursos hídricos superficiais ocorre na bacia Amazônica (Acre, Amazonas, Rondônia, Roraima, Amapá e em parte do Pará e do Mato Grosso), em contraposição aos estados da região nordeste (Maranhão, Piauí, Ceará, Rio Grande do Norte, Paraíba, Pernambuco, Alagoas, Sergipe e Bahia), os quais apresentam menor disponibilidade hídrica superficial (AGÊNCIA NACIONAL DE ÁGUAS [ANA], 2013).

O consumo e alocação da água possuem características próprias e variam de acordo com a estrutura produtiva e a configuração geográfica e temporal de cada região. Geralmente, em regiões caracterizadas pela agropecuária, o uso da água no processo de produção se torna mais intensivo, de forma a refletir de forma mais intensa na utilização dos recursos naturais. A ideia de "água virtual" baseia-se no conceito de água embutida, e tem despertado interesse crescente em diversas partes do mundo a partir de publicações sobre o tema com o objetivo de demonstrar a importância da gestão da água (HOEKSTRA; HUANG, 2002; HOEKSTRA, 2013).

A abordagem acerca do conceito de "água virtual" possibilita a mensuração do seu saldo decorrente do comércio internacional entre o estado de Mato Grosso do Sul e o resto do mundo, de modo a verificar se ele se encontra superavitário ou deficitário em relação aos principais produtos que são comercializados com outros países.

O território sul-mato-grossense é formado por bacias sedimentares do Paraná e do Pantanal. A Bacia do Paraná ocupa aproximadamente $65 \%$ da área do Estado, enquanto que a Bacia do Pantanal abrange 27\%, e o embasamento cristalino apenas 8\% (MATO GROSSO DO SUL, 2010).

Os cálculos envolvidos nas estimativas do volume de comercialização de água virtual, no entanto, são complexos. Para estimar esses valores, deve-se considerar a água envolvida em toda a cadeia de produção, assim como as características específicas de cada região produtora. Nesse sentido, a concepção de "água virtual" está relacionada intimamente ao conceito de "pegada hídrica", pois é necessário perseguir os passos e etapas do processo de produção, avaliando detalhadamente cada elemento.

Para o cálculo da pegada hídrica, considera-se o somatório da pegada hídrica direta (uso direto consumo e poluição da água no processo produtivo) e indireta (uso indireto do consumo e poluição da água no processo produtivo), utilizada na produção de determinado bem ou serviço. O uso indireto da água é calculado multiplicando-se todos os produtos consumidos por suas respectivas pegadas hídricas.

Mato Grosso do Sul, assim como o Brasil, é um importante produtor de bens agropecuários, assumindo posição de destaque, não somente na economia nacional, mas também no comércio exterior. Segundo o IBGE (2013), em 2013 o setor agropecuário foi responsável por 5,7\% do PIB brasileiro. Em conformidade com o Ministério da Agricultura, Pecuária e Abastecimento (MAPA) (BRASIL, 2014), nesse mesmo ano, as exportações do setor agropecuário atingiram 34,76\% do total das exportações brasileiras, enquanto as importações desse segmento representaram apenas $5,21 \%$, o que contribui para gerar um saldo positivo na balança comercial do setor.

O Estado é considerado um dos maiores produtores de gado e soja do Brasil e enfrenta situações diversas que incorrem no aumento do consumo da água, como o crescimento do setor sucroalcooleiro e da indústria de celulose, que possuem relações profundas com a questão hídrica.

Considerando que a água é um importante insumo necessário para a produção agropecuária e que Mato Grosso do Sul se destaca na produção e exportação de produtos desse setor, o 
presente artigo possui como questão norteadora: Como a inserção internacional impacta sobre a disponibilidade e qualidade dos recursos hídricos desse Estado?

Busca-se com o desenvolvimento do presente estudo fazer um balanço relativo à "água virtual" presente nas relações de comércio internacional de produtos exportados e importados durante o ano de 2013 entre Mato Grosso do Sul outros países. Sendo assim, apesar da forte ligação desse estado como outros estados da federação, o foco da pesquisa limitou-se a analisar as condições de consumo de água virtual em relação ao comércio internacional a despeito dos fluxos externos (caso de outros estados), em relação a determinados produtos agropecuários e industriais selecionados.

\section{CONSIDERAÇõES TEÓRICAS SOBRE O CONCEITO DE “ÁGUA VIRTUAL”}

Segundo Allan (2003), o termo água virtual foi introduzido a partir de meados de 1980, através da designação de "água embutida" pelo economista israelense Gideon Fishelson. Desde então, as discussões acerca do tema se destacam cada vez mais entre economistas, ambientalistas e instituições de Estado.

A partir da década de 1990, o termo "água virtual" passou a ser muito mais divulgado com as publicações de A. Y. Hoekstra. De acordo com Hoekstra e Hung (2002), entende-se como água virtual a quantidade total de água utilizada no processo de produção de um produto agrícola ou industrial. Os autores destacam que um país com escassez de água pode necessitar importar produtos intensivos em água e exportar produtos menos intensivos nesse recurso, o que implica necessariamente em exportação e importação de água na forma virtual.

Cabe destacar a diferença entre os conceitos de pegada hídrica e água virtual. Segundo Hoekstra et al. (2011), enquanto pegada hídrica se refere ao tipo da água utilizada no processo produtivo (verde, azul, cinza), água virtual possui um significado mais restrito e refere-se à quantidade de água embutida em um produto. Dessa forma, esse conceito melhor retrata o contexto internacional, ao abordar o volume de água na forma virtual decorrente da exportação ou importação de um produto, que é o objeto de estudo do presente trabalho.

Usamos o termo 'água virtual' no contexto internacional (ou inter-regional) de fluxos de água virtual. Se um país (ou região) exporta/importa um produto, ele está exportando/ importando água de modo virtual. Neste contexto, pode-se falar sobre a exportação ou importação da água virtual ou, de forma mais geral, sobre os fluxos ou o comércio de água virtual. (HOEKSTRA et al., 2011, p. 42).

Por outro lado, entende-se por pegada hídrica de um produto a soma das pegadas azul, verde e cinza, diferentemente do cálculo da água virtual, que considera apenas o total da quantidade de água utilizada no processo, sem observar, separadamente, o volume de cada tipo utilizado (azul, verde e cinza).

De acordo com Hoekstra et al. (2011), a pegada hídrica azul refere-se ao volume total da água azul presente no produto e utilizada no processo produtivo deste. A água azul diz respeito à água doce superficial, dos rios e lagos que se encontram na superfície terrestre e subterrânea, aquela que está no subsolo ou pode ser descrita como umidade de solo.

A água verde é aquela relacionada à precipitação no continente, que não escoa ou não repõe a água subterrânea, mas é armazenada no solo ou permanece temporariamente na superfície do solo ou na vegetação. Eventualmente, essa parte da precipitação evapora ou é transpirada 
pelas plantas. Sendo assim, a pegada hídrica verde, relaciona-se ao volume de água proveniente da chuva que foi consumida ao longo do processo produtivo.

A pegada hídrica cinza é definida como sendo a quantidade de água limpa necessária para diluir a água poluída, que resulta do processo produtivo de um determinado produto, até que esta fique dentro dos níveis aceitáveis.

Quando considerado por tonelada de produtos, destacam-se entre mercadorias com relativas elevadas pegadas de água: café, chá, cacau, tabaco, especiarias, castanhas, borracha e fibras. Para culturas alimentares, a pegada hídrica média global por tonelada de culturas aumenta a partir de culturas de açúcar (cerca de $200 \mathrm{~m}^{3} \mathrm{t}^{-1}$ ), legumes $\left(300 \mathrm{~m}^{3} \mathrm{t}^{-1}\right)$, raízes e tubérculos (400 $\mathrm{m}^{3} \mathrm{t}^{-1}$ ), frutas (cerca de $1000 \mathrm{~m}^{3} \mathrm{t}^{-1}$ ), cereais (cerca de $1600 \mathrm{~m}^{3} \mathrm{t}^{-1}$ ), oleaginosas (cerca de 2400 $\mathrm{m}^{3} \mathrm{t}^{-1}$ ), e leguminosas (cerca de $4000 \mathrm{~m}^{3} \mathrm{t}^{-1}$ ), (MEKONNEN; HOEKSTRA, 2011).

No entanto a pegada de água varia de acordo com a safra e pode revelar-se bastante heterogênea da média global para regiões específicas. As variações da pegada hídrica de determinadas culturas entre países ou regiões ocorrem, principalmente, devido às diferenças de produtividade. Após calcular as pegadas de água por tonelada de cereais na Europa, verificou-se uma variação entre o Norte $\left(637 \mathrm{~m}^{3} \mathrm{t}^{-1}\right)$,) e Leste $\left(654 \mathrm{~m}^{3} \mathrm{t}^{-1}\right)$,) desse continente para o mesmo tipo de cultura. Da mesma forma, em muitas partes da África, com a exceção da África do Sul, as pegadas hídricas das culturas de cereais são elevadas (MEKONNEN; HOEKSTRA, 2011).

\section{MATO GROSSO DO SUL: CARACTERÍSTICAS TERRITORIAIS}

\subsection{Aspectos ambientais e hídricos de Mato Grosso do Sul}

Localizado na região Centro-Oeste do Brasil, o Estado de Mato Grosso do Sul abrange três importantes biomas brasileiros: o Cerrado, a Mata Atlântica e o Pantanal. O Cerrado é um tipo de savana que ocorre no Brasil onde se destaca a presença, em diferentes proporções, de formações herbáceas, arbustivas e arbóreas. Esse bioma ocupa mais de 205,9 milhões de hectares na porção central do Brasil, e representa o segundo bioma brasileiro em termos de riqueza de biodiversidade ainda que em avançado grau de devastação (INSTITUTO BRASILEIRO DE FLORESTAS, 2016).

A Mata Atlântica corresponde a 13,04\% do território nacional e encontra-se localizada principalmente ao longo da costa litorânea que vai do Rio Grande do Norte ao Rio Grande do Sul. Apresenta uma variedade de formações de ecossistemas florestais com estrutura e composições florísticas bastante diferenciadas, acompanhando as características climáticas da região onde ocorre (INSTITUTO BRASILEIRO DE FLORESTAS, 2016). Cerca de 70\% da população brasileira vivem no território da Mata Atlântica, as nascentes e mananciais abastecem as cidades, esse é um dos fatores que tem contribuído com os problemas de crise hídrica, associados à escassez, ao desperdício, à má utilização da água, ao desmatamento e à poluição, fato que corrobora com a degradação desse ecossistema.

O bioma Pantanal é considerado uma das maiores extensões úmidas contínuas do planeta. No Brasil, é considerado o de menor extensão territorial com uma área aproximada de 150.355 $\mathrm{km}^{2}$, ocupando assim $1,76 \%$ da área total do território brasileiro. O Pantanal sofre influência direta de três importantes biomas brasileiros: Amazônia, Cerrado e Mata Atlântica. Além disso sofre influência do bioma Chaco (nome dado ao Pantanal localizado no norte do Paraguai e leste da Bolívia). No entanto esse bioma vem sendo muito impactado pela ação humana, principalmente 
em decorrência da atividade agropecuária, caracterizada pelo uso extensivo de grandes áreas de pastagens (BRASIL, 2016).

No que se refere às características hídricas, o território sul-mato-grossense encontra-se localizado em posição estratégica, cercado por duas grandes bacias hidrográficas formadas pelos rios Paraná (a Leste) e Paraguai (a Oeste), que ilustram, além da riqueza desse bioma, suas possibilidades de integração por meio de hidrovias com estados e países vizinhos. Como principal divisor de águas entre essas duas importantes bacias, situam-se a Serra das Araras, a Serra de Camapuã e parte da Serra de Maracaju (Figura 1).

Figura 1- Bacias Hidrográficas do Rio Paraná e Rio Paraguai do Estado de Mato Grosso do Sul

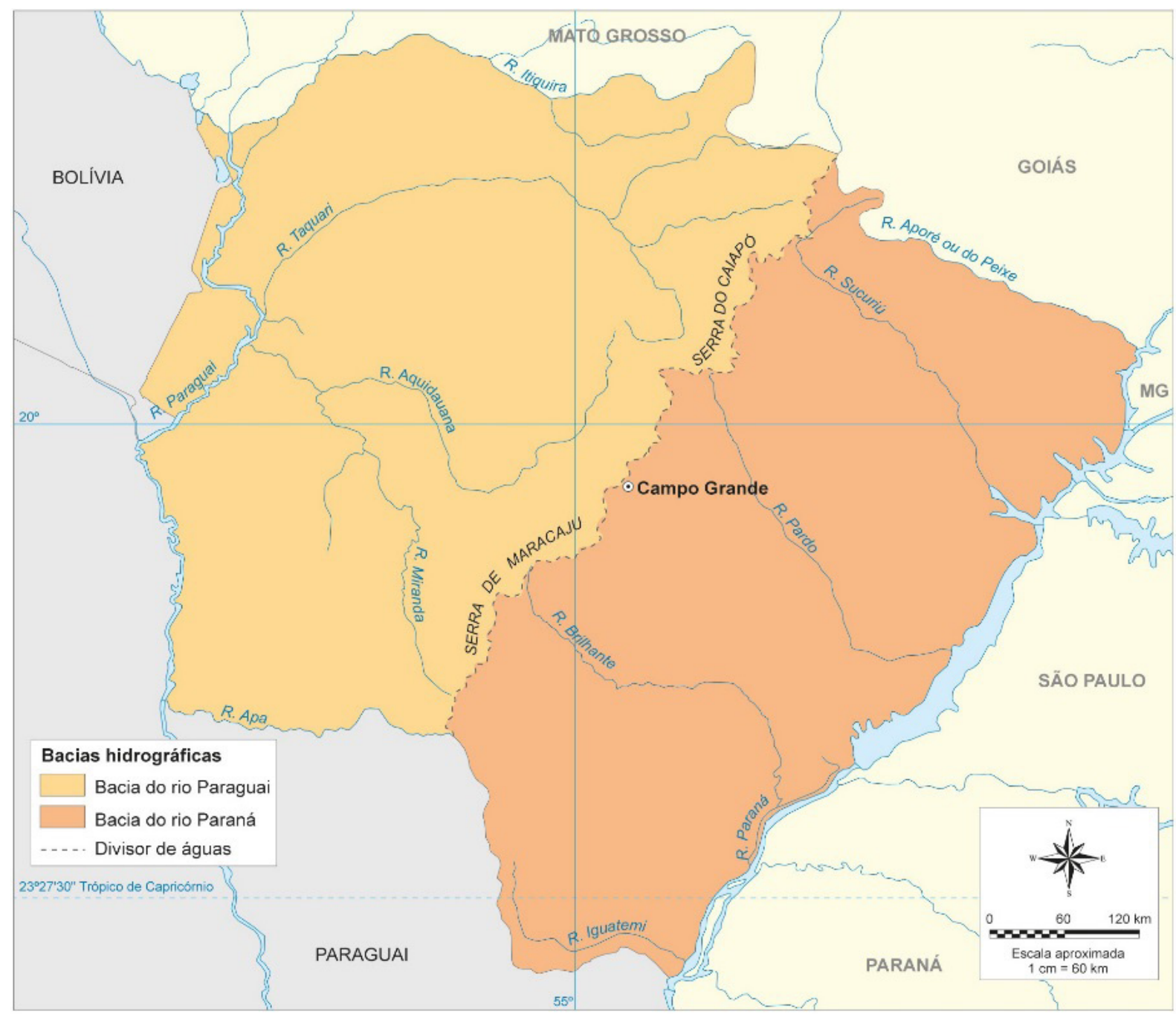

Fonte: Instituto do Meio Ambiente de Mato Grosso do Sul (IMASUL, 2014).

A bacia hidrográfica do Rio Paraná é constituída de chapadões, planaltos e vales. Conforme ilustra a Figura 1, destacam-se entre seus afluentes, os rios Quitéria, Aporé ou do Peixe, Sucuriú, Verde, Pardo, Ivinhema, Amambai, Santana e Iguatemi. Essa bacia se destaca pelo potencial hidrelétrico, em parte já aproveitado, como é o caso do rio Pardo, onde está implantada a Usina de Salto Mimoso, e do rio Paraná, onde se destacam as Usinas de Jupiá e Ilha Solteira, integrando o Complexo Urubupungá. Encontra-se também nessa região a Usina de Porto Primavera, na fronteira com o estado de São Paulo. 
No que tange à bacia hidrográfica do Paraguai, destacam-se além do próprio Rio Paraguai, que é um rio de planície com condições de navegabilidade em cerca de $90 \%$ do seu curso (MATO GROSSO DO SUL, 2015), os rios Correntes, Taquari, Nabileque, Aquidauana, Miranda, Negro e Apa. O potencial hidrelétrico é pequeno, comparado com a bacia do Paraná, verificando-se apenas usinas de pequeno porte, como as de São João I e São João II, no Rio São João; São Gabriel do Oeste, no rio Coxim, e César Galvão, no rio Taquarizinho.

Destaca-se ainda o sistema de águas subterrâneas ou sistemas aquíferos identificados por dois grandes grupos de rochas, as sedimentares, definindo os aquíferos porosos, e as ígneasmetamórficas, que constituem os aquíferos fraturados ou de fissuras. Os aquíferos porosos ocorrem nas bacias sedimentares do Paraná e do Pantanal, e os fraturados, no embasamento cristalino e em uma formação da Bacia do Paraná (MATO GROSSO DO SUL, 2010).

O Estado de Mato Grosso do Sul possui oito unidades aquíferas: Sistema Aquífero Cenozóico; Sistema Aquífero Bauru; Sistema Aquífero Serra Geral; Sistema Aquífero Guarani; Sistema Aquífero Aquidauana-Ponta Grossa; Sistema Aquífero Furnas; Sistema Aquífero Pré-cambriano Calcários e, Sistema Aquífero Pré-cambriano.

Em termos de distribuição percentual em área, os Aquíferos Bauru e Cenozoico são os de maior área de afloramento, ambos Aquíferos livres, com respectivamente 37\% e 27\% da área total de Mato Grosso do Sul. A distribuição na Região Hidrográfica do Paraná mostra a importância dos Aquíferos Bauru e Serra Geral, com 75\% e 24\% de área, respectivamente, além do Aquífero Guarani, com área de afloramento de apenas 0,1\% da área dessa Região Hidrográfica.

A Região Hidrográfica do Paraguai caracteriza-se por maior diversidade de afloramentos de Aquíferos, sendo o de maior expressão em área o Aquífero Cenozoico, com 51\% da área desta Região Hidrográfica, seguido pelo Aquífero Pré-cambriano, com 12\%, pelos Aquíferos Guarani e Pré-cambriano Calcários, com 12\%, o Aquífero Aquidauana Ponta Grossa, com 9\%, o Aquífero Serra Geral, com 6\% e os Aquíferos Furnas e Bauru, com aproximadamente 3\% da área. É importante ressaltar que, nessa Região Hidrográfica, tais aquíferos não se encontram sobrepostos.

\subsection{Aspectos produtivos e de comércio exterior de Mato Grosso do Sul}

A atividade econômica sul-mato-grossense encontra-se assentada na agroindústria, sobretudo na produção de commodities, potencializada pelo uso dos seus recursos naturais, dos solos agricultáveis, da abundância de matéria prima, dos benefícios fiscais, da configuração de novos eixos logísticos, apostando na ampliação e modernização da produção agropecuária e industrial, centrada nas culturas de grãos e na pecuária de corte. A pecuária de corte foi muito incrementada a partir do início da década de 1990, devido à atração de investimentos nos setores da avicultura, da suinocultura de corte, beneficiamento de grãos e indústrias nas áreas de carne e leite, entre outros.

Apesar dessa nova dinâmica, o Estado de Mato Grosso do Sul caracteriza-se por ter uma economia de base agropastoril, cujas atividades de extração vegetal, pecuária e agricultura encontram-se presentes desde o início da ocupação do seu território. O Estado possui forte vocação agrícola destacando-se entre os maiores produtores de grãos do Brasil, com elevada produção e produtividade principalmente nas culturas de soja, milho e cana-de-açúcar (Tabela 1). 
Tabela 1- Produção das principais culturas agrícolas de Mato Grosso do Sul - 2005-2013 (em toneladas)

\begin{tabular}{lcrr}
\hline Produção & $\mathbf{2 0 0 5}$ & $\mathbf{2 0 1 0}$ & \multicolumn{1}{c}{$\mathbf{2 0 1 5}$} \\
\cline { 2 - 4 } & $\mathbf{( t )}$ & \multicolumn{1}{c}{$\mathbf{~} \mathbf{~}$} & \multicolumn{1}{c}{$\mathbf{~}$} \\
\hline Soja & 3.686 .132 & 5.340 .462 & 7.305 .608 \\
Milho & 1.305 .741 & 3.782 .946 & 9.552 .500 \\
Arroz & 225.350 & 142.668 & 99.287 \\
Algodão & 203.391 & 149.369 & 137.724 \\
Trigo & 129.683 & 74.207 & 31.769 \\
Sorgo & 19.004 & 31.937 & 47.540 \\
Cana-de-açúcar & 9.513 .818 & 34.795 .664 & 51.222 .400 \\
\hline
\end{tabular}

Fonte: Dados da pesquisa a partir de IBGE (2016).

Em relação à pecuária, o estado sul-mato-grossense se destaca pela criação de bovinos, aves, suínos, equinos, ovinos, muares, caprinos e bubalinos. Os segmentos da pecuária desempenham expressivo papel na ocupação econômica e produção de carnes e outros produtos de origem animal, como lácteos, couro e ovos. Em Mato Grosso do Sul, destacamse, especificamente, as atividades de bovinocultura (cerca de 21 milhões de cabeças em 2014, segundo dados do IBGE) e avicultura (cerca de 1,3 bilhões de cabeças no mesmo ano).

No que tange ao comércio internacional, Mato Grosso do Sul vem apresentando desempenho satisfatório ao longo dos anos, sobretudo a partir do processo de abertura da economia brasileira. Os dados mostram que, no início dos anos de 1990, o Estado tinha um intercâmbio comercial (somatório das exportações mais importações) de, aproximadamente, US\$ 185 milhões no âmbito do comércio internacional; já, em 2013, esse fluxo comercial somava um montante de US\$ 10,8 bilhões.

Tabela 2- Exportações e importações por fatores agregados, 2003-2013, do Estado de Mato Grosso do Sul

\begin{tabular}{|c|c|c|c|c|}
\hline \multirow{2}{*}{ Período } & \multicolumn{2}{|c|}{ Exportações (US\$ 1000 FOB) } & \multicolumn{2}{|c|}{ Importações (US\$ 1000 FOB) } \\
\hline & Básicos & Industrializados & Básicos & Industrializados \\
\hline 2003 & 369.237 & 129.102 & 388.494 & 104.374 \\
\hline 2004 & 435.204 & 209.550 & 593.416 & 178.537 \\
\hline 2005 & 880.866 & 268.256 & 814.085 & 265.927 \\
\hline 2006 & 730.403 & 273.337 & 1.296 .313 & 429.524 \\
\hline 2007 & 994.777 & 300.630 & 1.554 .709 & 635.179 \\
\hline 2008 & 1.691 .621 & 401.713 & 2.797 .986 & 884.580 \\
\hline 2009 & 1.337 .687 & 599.215 & 1.682 .464 & 1.007 .766 \\
\hline 2010 & 1.916 .391 & 1.043 .435 & 2.262 .797 & 1.119 .865 \\
\hline 2011 & 2.443 .236 & 1.471 .022 & 2.906 .857 & 1.562 .210 \\
\hline 2012 & 2.647 .522 & 1.563 .133 & 3.468 .320 & 1.645 .651 \\
\hline 2013 & 3.391 .806 & 1.864 .181 & 3.921 .233 & 1.734 .296 \\
\hline
\end{tabular}

Fonte: Dados da pesquisa a partir de SEMADE (MATO GROSSO DO SUL, 2015). 
Através da Tabela 2, verifica-se que existe uma maior participação dos produtos básicos sobre as exportações do MS. Embora as exportações dos produtos industrializados tenham apresentado uma tendência de aumento, passando de uma participação de aproximadamente $25 \%$, em 2003, para aproximadamente $36 \%$ sobre o total das exportações sul-mato-grossenses, em 2013, em sua maioria tais exportações encontravam-se relacionadas às atividades do agronegócio.

Destacaram-se entre os principais produtos exportados em 2013: soja "in natura" (23\%), pasta química de madeira (19\%), carnes desossadas de bovinos, congeladas (9,5\%), outros açúcares de cana (9,5\%), milho "in natura" (8,2\%), minérios de ferro (7,5\%), e demais produtos (23,3\%) (MATO GROSSO DO SUL, 2015).

No que se refere aos principais destinos de exportação dos produtos do Estado, destacase a Ásia responsável pela maioria absoluta da compra dos produtos exportados (48,33\%) pelo MS. Nesse cenário, destaca-se a China como o principal parceiro comercial sul-mato-grossense no mercado internacional, e que foi responsável em 2013, por 28,23\% de todo o faturamento das exportações de Mato Grosso do Sul. Destacaram-se entre os produtos comercializados a celulose, pedaços e miudezas comestíveis congelados de galos e galinhas, e o açúcar. Além da China, a União Europeia apresenta posição de destaque ocupando a segunda posição no ranking $(15,3 \%)$ das exportações de MS, tendo a Holanda se destacado como maior parceiro comercial, e na sequência, a Itália. (BRASIL, s.d.).

Por outro lado, na pauta de importações, os itens mais representativos são: gás natural, produtos do cobre, material elétrico, cloreto de potássio, têxteis e tecidos, carnes desossadas de bovinos, máquinas e equipamentos, adubos e fertilizantes (MATO GROSSO DO SUL, 2015).

Em se tratando da origem das importações sul-mato-grossenses, destacam-se os países da América Latina, sobretudo a Bolívia, de onde se importa o gás natural, representou cerca de $60 \%$ do volume total importado em 2013. Entre outros itens representativos das importações desse Estado, destacam-se produtos do cobre, material elétrico, cloreto de potássio, têxteis e tecidos, carnes desossadas de bovinos, máquinas, adubos e fertilizantes (MATO GROSSO DO SUL, 2015).

\section{METODOLOGIA E FONTE DE DADOS}

\subsection{Mensuração da água virtual na composição da Balança Comercial Sul-Mato-Grossense}

Metodologicamente o trabalho baseia-se em uma pesquisa descritiva com levantamento e tabulação de dados secundários referentes ao ano de $2013^{4}$, obtidos junto a fontes tais como: Secretaria de Estado de Meio Ambiente e Desenvolvimento Econômico de Mato Grosso do Sul (SEMADE/MS); Ministério do Desenvolvimento da Indústria e do Comércio (MDIC); e Instituto Brasileiro de Geografia e Estatística (IBGE). Para o cálculo da economia de água relacionada ao comércio internacional, utilizou-se o modelo proposto por Hoekstra et al. (2011), equação (1).

$$
E n[p]=\left(T i[p]-T e[p] \times \operatorname{PHprod}[p] \quad\left[\operatorname{volume} \times \text { tempo }^{-1}\right]\right.
$$

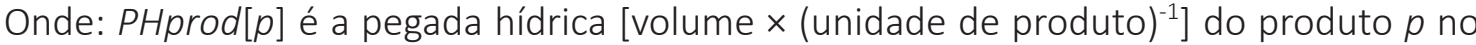
país em questão, Ti[ $p$ ] o volume do produto $p$ importado (unidade de produto $\times$ tempo $^{-1}$ ) e Te $[p]$ o volume do produto exportado (unidade de produto $\times$ tempo $^{-1}$ ).

\footnotetext{
${ }^{4}$ Dados da última matriz insumo produto de Mato Grosso do Sul.
} 
A pegada hídrica dos produtos utilizados para estimar as balanças de água virtual propostas pelo estudo, encontram-se disponíveis em Mekonnen e Hoekstra (2011) tendo como base o período de 1996 a 2005. Neste, ponto é importante que sejam feitas algumas observações: i) são considerados apenas os produtos para os quais há informações a respeito da quantidade de água virtual deles; ii) entre os produtos de origem agropecuária foram consideradas as categorias da soja, milho, aves e ovos, bovinos, leite e outros produtos da lavoura. Entre os produtos industrializados, destacam-se: bovino industrializado, carnes de aves frescas, refrigeradas ou congeladas, pescado industrializado e produtos do laticínio e sorvetes. Nas atividades referentes ao cultivo da cana e criação de suínos não constaram dados tanto de exportação quanto de importação; iii) a informação relativa à pegada de água embutida na elaboração dos produtos como um todo diz respeito à média sul-mato-grossense para produtos de origem vegetal; iv) a informação relativa à pegada de água embutida na elaboração dos produtos como um todo diz respeito à média brasileira para produtos de origem animal e industrial; e v) O cálculo do balanço de água virtual foi realizado a partir do valor agregado dos produtos.

Faz-se necessário destacar uma diferenciação entre a balança de água virtual proposta por este trabalho e a balança comercial como se conhece. Enquanto as exportações são positivas e as importações negativas, neste trabalho as exportações passam a ser negativas, pois representam "saída" de água do Estado e as importações se tornam positivas, pois caracterizam "entrada" de água no estado.

\subsection{Matriz insumo produto}

O uso de modelos de insumo-produto em questões relacionadas à água tem ganhado notoriedade na bibliografia internacional. Duarte e Yang (2011) utilizam a metodologia de insumo-produto como método de análise dedicada a estudar questões referentes aos recursos hídricos, em suas diversas aplicações: captação, lançamento de poluentes, comércio de água virtual, pegada hídrica, "água azul", demanda por água, entre outros. Por sua vez Wiedmann et al. (2007) realizou uma análise mais ampla dos modelos de insumo-produto publicados até então e aplicados em estudos sobre recursos naturais, inclusive água, destacando a importância dos modelos multirregionais.

A matriz de insumo-produto decompõe os fluxos entre as atividades econômicas e os fatores primários, descrevendo a estrutura interna de cada setor produtivo e do conjunto da economia. Dessa forma, torna um instrumento importante para avaliar as interdependências entre os setores produtivos, possibilitando identificar os requerimentos de água para a produção e posterior consumo podendo definir os efeitos sobre o comércio de água virtual. Além disso, ela também possibilita medir o impacto de políticas públicas, auxiliando no planejamento econômico.

A equação (1) pode ser escrita em forma matricial como:

$$
A x+y=x
$$

Sendo A é a matriz de coeficientes diretos de insumo de ordem $(n \times n)$ e x e y são vetores colunas de ordem ( $n \times 1)$.

Resolvendo a equação (2) é possível se obter a produção total que é necessária para satisfazer a demanda final equação (3).

$$
x=(I-A)^{-1} y
$$


Sendo $(I-A)^{-1}$ é a matriz de coeficientes diretos e indiretos, ou a matriz de Leontief. Fazendo $B=(I-A)^{-1}$, o elemento $b_{i j}$ deve ser interpretado como sendo a produção total do setor i que é necessária para produzir uma unidade de demanda final do setor $j$.

Se houver um aumento da demanda por produtos de determinado setor $j$, o impacto inicial corresponderá exatamente ao aumento da produção deste setor. Essa variação está refletida no primeiro termo / do somatório $\left(I+A+A^{2}+A^{3}+\ldots+A^{n}\right)$. Mas, para aumentar a produção, o setor $j$ demandaria insumos dos demais setores, segundo a proporção estabelecida pela coluna j. Pré-multiplicando o vetor da variação da demanda pela matriz $(I-A)^{-1}$ chega-se ao seguinte resultado: o setor $j$ teria um aumento de produção correspondente à variação da demanda mais o valor necessário de insumo demandado pelo próprio setor em função do aumento da demanda final. Todos os demais setores que fornecem insumos ao setor $j$ também teriam suas produções alteradas. O acréscimo seria correspondente à variação da demanda vezes o coeficiente técnico $a_{i j}$

\section{RESULTADO E DISCUSSÃO}

\subsection{Balança de água virtual}

De acordo com os resultados obtidos, o estado de Mato Grosso do Sul apresentou-se como exportador líquido de água virtual para os produtos selecionados, no ano de 2013. Para a análise da balança de água virtual, consideraram-se dois grupos de produtos: o agropecuário, abrangendo a coleta de informações de atividades ligadas ao plantio da soja e milho, e o da criação e produção de produtos de origem animal. No segmento de industrializados, considerou-se a produção de derivados da carne e leite obtidos através de algum tipo de processamento fabril.

Tabela 3- Balança de água virtual de Mato Grosso do Sul, por $\mathrm{m}^{3} / \mathrm{mil}_{\text {l }}$ toneladas, em 2013

\begin{tabular}{|c|c|c|c|c|c|}
\hline Produto & $\begin{array}{c}\text { Exportação } \\
t\end{array}$ & $\begin{array}{c}\text { Importação } \\
\text { t }\end{array}$ & $\begin{array}{c}\text { Saldo } \\
t\end{array}$ & $\begin{array}{c}\text { Peg. Água } \\
\mathrm{m}^{3} \text { (água) } \times \mathrm{t}^{-1}\end{array}$ & Água Virtual \\
\hline \multicolumn{6}{|l|}{ AGROPECUÁRIO } \\
\hline Soja & -2.279 .961 .4 & $65.904,1$ & $-2.214,1$ & 2.544 & $-5.632 .561,6$ \\
\hline Milho & $-1.851 .006,9$ & $11.286,4$ & $-1.839,7$ & 2.970 & $-5.463 .969,8$ \\
\hline Aves e ovos & $-79,1$ & 0 & $-0,1$ & 2.295 & $-181,4$ \\
\hline Bovinos & $-293,0$ & 0 & $-0,3$ & 8.115 & $-2.377,4$ \\
\hline Leite & $-2.712,6$ & 24,0 & $-2,7$ & 2.572 & $-6.915,2$ \\
\hline $\begin{array}{l}\text { Outros produtos da } \\
\text { lavoura }\end{array}$ & $-380,2$ & $2.681,8$ & 2,3 & 5.562 & $12.801,3$ \\
\hline \multicolumn{6}{|l|}{ INDUSTRIALIZADO } \\
\hline Bovino industrializado & $-15.275,6$ & $15.180,7$ & $-0,1$ & $1.6879,0$ & $-1.601,8$ \\
\hline $\begin{array}{l}\text { Aves frescas, cong. e } \\
\text { refrigeradas }\end{array}$ & $-138.880,3$ & 415,7 & $-138,5$ & $4.204,0$ & $-58.2105,0$ \\
\hline Laticínios e sorvetes & $-1,3$ & 68,0 & $-0,1$ & $4.908,0$ & $-340,2$ \\
\hline
\end{tabular}

Fonte: Dados da pesquisa a partir de dados do MDIC (BRASIL, s.d.) e Hoekstra et al. (2011).

Conforme dados da Tabela 3, entre os principais produtos exportadores de água para o resto do mundo, destacam-se, no setor agropecuário, a soja e o milho e, no setor industrial, as atividades ligadas ao beneficiamento de aves frescas, congeladas e refrigeradas. Isso indica que o estado exporta mais produtos que utilizam em seu processo produtivo, um volume maior de água, comparativamente aos produtos importados em questão. 
Levando-se em consideração o destino das exportações de Mato Grosso do Sul, destacamse, entre os principais importadores de água virtual do Estado, a Ásia (exclusive Oriente Médio) e a Europa. A China representa o principal comprador de soja do Estado, destinada para o abastecimento do parque industrial daquele país.

Por outro lado, MS se destaca como importador de água no segmento de outros produtos da lavoura, considerando-se a entrada de grãos de feijão, sobretudo importados da Bolívia, sementes de gergelim importadas da Índia e plantas medicinais e afins compradas do Chile, China, Egito e Índia.

A grande participação do setor agrícola no consumo de água se explica principalmente pelo uso da água para irrigação. Segundo Carmo et al. (2007), as áreas irrigadas no Brasil vêm aumentando como alternativa estratégica para aumentar a oferta de produtos agrícolas. Entretanto é necessário que haja um manejo racional da irrigação, considerando não apenas as técnicas mais modernas, mas também a aplicação das quantidades adequadas para cada tipo de cultura nos períodos ótimos, de maneira a evitar desperdícios de energia e de água.

Cruzando-se a produção dos principais produtos comercializados por Mato Grosso do Sul, verifica-se que a região maior exportadora de água virtual concentra-se no eixo centro-sul do Estado, nas regiões de cerrado. A produção de soja concentra-se nas áreas de planejamento da Grande Dourados e Sul-Fronteira, destacando-se entre os municípios produtores, os municípios de Maracaju, Dourados, Douradina, Fátima do Sul, Laguna Carapã, Aral Moreira, Deodápolis, Rio Brilhante, Sidrolândia, Itaporã e Ponta Porã. A cultura do milho concentra-se na região Sudoeste do Estado, abrangendo as microrregiões de Bodoquena, Dourados e Iguatemi.

Destacam-se, também, como regiões produtoras do milho e soja, as regiões localizadas sobre as microbacias hidrográficas do Rio Ivinhema, Amambai e Iguatemi, pertencentes à Bacia do Paraná.

\subsection{Análise da matriz insumo produto e a prospecção de cenários}

Com as quantidades de exportações dos produtos selecionados, junto da matriz insumo produto de Mato Grosso do Sul de 2013, podemos traçar alguns cenários variando as quantidades de exportações dos produtos, o que por sua vez, nos dará a dimensão dos produtos produzidos e, por consequência, do papel da água na economia sul- mato-grossense.

Primeiramente, faz-se necessário elucidar a importância dos produtos (sobretudo a soja e o milho) tratados neste trabalho, adotando-se para isso os índices normalizados de Rasmussen (RAMUSSEN, 1956; HIRSCHMAN, 1958) provenientes da matriz insumo-produto do estado de Mato Grosso do Sul de 2013. Esse índice permite identificar o poder de dispersão de um setor $j$ nas demais indústrias, ou seja, o incremento total (direto e indireto) na produção setorial dessas demais indústrias em atender a um incremento na demanda final do setor j. É representado formalmente como:

$$
\frac{\frac{1}{n} \sum_{j} b_{i j}}{\frac{1}{n^{2}} \sum_{i} \sum_{j} b_{i j}} \quad(i, j=1,2, \ldots, n)
$$

onde $b=$ os elementos da matriz $(I-A)^{-1}$. 
Tabela 4- Índices de Rasmussen normalizados, setores selecionados de Mato Grosso do Sul, em 2013

\begin{tabular}{lcc}
\hline Produtos & Para trás & Para frente \\
\hline Agricultura sem a soja e o milho & 0,942 & 1,432 \\
Milho em grão & 0,893 & 0,847 \\
Soja em grão & 0,909 & 1,469 \\
Pecuária e pesca & 1,166 & 1,049 \\
Fabricação de óleos vegetais- exceto milho & 1,476 & 0,972 \\
Fabricação de óleo de milho e rações & 1,603 & 0,796 \\
Celulose e produtos de papel & 1,137 & 0,959 \\
\hline
\end{tabular}

Fonte: Elaborado pelos autores a partir de Rasmussen (1956) e Hirschman (1958).

O índice de Rasmussen para frente é calculado a partir da soma das linhas da inversa da matriz (I - A), sendo posteriormente normalizado para fins de melhor interpretação. Na tabela anterior, temos que, índices maiores que 1 são produtos significativamente fornecidos para as demais cadeias produtivas. Nos índices "para trás"- soma das colunas - temos o inverso, ou seja, temos a compra dos produtos pelos setores. Quando ambos são maiores que 1, temos então caracterizado um setor "chave" na economia.

Focando nos produtos em questão neste trabalho, temos a soja em grão como como um produto estimulador de outros setores (para frente), bem como a fabricação de seus óleos como setor chave, com índice para trás e para frente de 1,46 e 1,43 respectivamente. Os produtos da pecuária e pesca, em que por sua vez é onde estão as Aves e ovos, Bovinos, Leite e demais derivados industrializados também se caracteriza um setor chave para o MS, com índices maiores que 1. No entanto, em relação ao milho, temos apenas o índice para trás significativo para a fabricação de óleos e rações, não apresentando ligações para trás ou para frente para grãos in natura.

Nesse contexto, temos que políticas econômicas de incentivo aos produtos industrializados são mais eficientes em termos de dinamização econômica dos que os produtos primários, que, por sua vez, possuem uma pegada de água virtual menor que os produtos primários (com exceção do bovino industrializado, que possui consumo de água alto se comparado aos outros produtos). Para exemplificar, podemos fazer um exercício simples de simulação, analisando as consequências ao longo das cadeias produtivas, bem como do consumo de água virtual adjacente a todo o processo.

Supõe-se, por exemplo, um estímulo razoável de 10\% na demanda por esses produtos através das exportações do MS para o resto do mundo, mantendo as importações constantes. Temos então um novo balaço de água virtual conforme dados da Tabela 5: 
Tabela 5- Balança de água virtual de Mato Grosso do Sul, por m³/mil toneladas, em 2013, aumento de $10 \%$ nas exportações

\begin{tabular}{|c|c|c|c|c|c|}
\hline PRODUTO & $\begin{array}{c}\text { EXPORTAÇÃO } \\
t\end{array}$ & $\begin{array}{c}\text { IMPORTAÇÃO } \\
t \\
\end{array}$ & $\begin{array}{c}\text { SALDO } \\
t\end{array}$ & $\begin{array}{l}\text { PEG. ÁGUA } \\
\mathrm{m}^{3} \text { (água) } \times \mathrm{t}^{-1}\end{array}$ & $\begin{array}{c}\text { ÁGUA } \\
\text { VIRTUAL }\end{array}$ \\
\hline \multicolumn{6}{|l|}{ AGROPECUÁRIO } \\
\hline Soja & $-2.507 .957,54$ & $65.904,10$ & $-2.442 .053,44$ & $2.544,00$ & $-5.632 .561,60$ \\
\hline Milho & - 2.036.107,59 & $11.286,40$ & $-2.024 .821,19$ & $2.970,00$ & - 5.463.969,80 \\
\hline Aves e ovos & $-87,01$ & 0 & $-87,01$ & $2.295,00$ & $-181,40$ \\
\hline Bovinos & $-322,30$ & 0 & $-322,30$ & $8.115,00$ & $-2.377,40$ \\
\hline Leite & $-2.983,86$ & 24,00 & $-2.959,86$ & $2.572,00$ & $-6.915,20$ \\
\hline $\begin{array}{l}\text { Outros produtos da } \\
\text { lavoura }\end{array}$ & $-418,22$ & $2.681,80$ & $2.263,58$ & $5.562,00$ & $12.801,30$ \\
\hline \multicolumn{6}{|l|}{ INDUSTRIALIZADO } \\
\hline $\begin{array}{l}\text { Bovino industrializa- } \\
\text { do }\end{array}$ & $-16.803,16$ & $15.180,70$ & $-1.622,46$ & $16.879,00$ & $-1.601,80$ \\
\hline $\begin{array}{l}\text { Aves frescas, cong. e } \\
\text { refrigeradas }\end{array}$ & $-152.768,33$ & 415,70 & $-152.352,63$ & $4.204,00$ & $-582.105,00$ \\
\hline Laticínios e sorvetes & $-1,43$ & 68,00 & 66,57 & $4.908,00$ & $-340,20$ \\
\hline
\end{tabular}

Fonte: Dados da pesquisa a partir de dados do MDIC (BRASIL, s.d.).

Como exercício simples, temos que nosso saldo em água virtual também piorou em $10 \%$, contudo houve ganho significativo no estímulo econômico, uma vez que os produtos industrializados e grande parte dos agropecuários possuem fortes elos com o resto da economia, como demonstrado pelos índices de Rasmussen na Tabela 4.

Tal fato se faz ainda mais relevante a partir da constatação, como descrito ao longo da caracterização dos recursos hídricos de Mato Grosso do Sul, de que o estado é rico em quantidade de água, sugerindo que, com o uso racional da água no processo produtivo como um todo, isso permitirá melhor posicionamento no mercado internacional através das exportações.

Entretanto é necessário atentar-se para a sua sustentabilidade ambiental a médio e longo prazo. Os recursos hídricos envolvidos na produção dos bens exportados podem acabar se tornando escassos até mesmo em regiões em que há relativa abundância, sobretudo, em regiões cuja geração de divisas está fortemente atrelada à exportação de produtos primários como a soja e o açúcar, ou ainda de produtos semimanufaturados, como cortes de carnes.

Nesse contexto, ressalta-se a importância na definição de políticas ambientais destinadas não somente ao tratamento da questão hídrica, como também de produção, transformação e distribuição das atividades produtivas no território sul-mato-grossense.

O Plano Estadual de Recursos Hídricos de Mato Grosso do Sul (PERH-MS), aprovado em 2009, é instrumento utilizado para subsidiar a tomada de decisão e direcionar o gerenciamento da questão hídrica no Estado, contudo muitos são os desafios para a aplicação dos mecanismos de gestão.

Algumas peculiaridades da legislação de Mato Grosso do Sul, que remetem à isenção da cobrança pelo uso da água pelo setor agropecuário e agroindustrial, às mudanças institucionais ocorridas no âmbito do Órgão Estadual de Recursos Hídricos e a falta de clareza nas competências entre o órgão gestor e o executor da Política de Recursos Hídricos do Estado, contribuem para a geração de dificuldades na implementação de fato desse instrumento. 
Desse modo, verifica-se a necessidade em definir estratégias mais eficazes no controle da exploração dos recursos hídricos, inclusive em regiões com abundância desse fator, e apontar mudanças tanto no plano político como institucional voltadas à superação de barreiras que limitam os avanços na implementação dos instrumentos de gestão no Estado.

\section{CONSIDERAÇÕES FINAIS}

No presente estudo, propôs-se estimar os montantes de usos de água virtual para os principais produtos de exportação de Mato Grosso do Sul no ano de 2013, tendo em vista cenários de crescimento econômico e da participação dessas atividades produtivas no mercado internacional.

A conclusão foi que o Estado é um exportador de água virtual para as atividades agropecuárias, sobretudo aquelas em que possui maiores competitividades e produtividade como o milho e soja. Além disso, verifica-se que as regiões de produção maiores exportadoras concentram-se na faixa centro-sul do Estado, localizadas principalmente na Bacia do Paraná.

Através dos dados levantados, sugere-se a necessidade de elaboração de políticas públicas, ambientais e econômicas, mais eficazes no controle hídrico, com o intuito de promover uso racional das reservas de água doce bem como a redução dos desperdícios de água no processo produtivo de cadeias do agronegócio que se caracterizam pelo elevado índice de pegada hídrica. Sobretudo, políticas econômicas de incentivo aos produtos industrializados que são mais eficientes em termos de dinamização econômica em relação aos produtos primários, e os quais costumam apresentar índices de pegada de água virtual menor que os produtos primários.

\section{REFERÊNCIAS}

ALLAN, J. A. Virtual water: the water, food and trade nexus, useful concept or misleading metaphor? IWRA, Water International, v. 28, n. 1, p. 4-11, mar. 2003. Disponível em: https://pdfs.semanticscholar. org/119e/706b7fe912aa235f74d85d5635ca8c125721.pdf

ANA. Conjuntura dos recursos hídricos no Brasil: 2013. Brasília: Agência Nacional de Águas - ANA, 2013. Disponível em: http://arquivos.ana.gov.br/institucional/spr/conjuntura/webSite_relatorioConjuntura/ projeto/index.html. Acesso em: 29 abr. 2014.

BANCO MUNDIAL. Renewable internal freshwater resources, total (billion cubic meters). 2014. Disponível em: https://data.worldbank.org/indicator/ER.H2O.INTR.K3?view=chart

BRASIL. Ministério do Meio Ambiente- MMA. Pantanal. Brasília, DF: MMA, 2016. Disponível em: http:// www.mma.gov.br/biomas/pantanal.

BRASIL. Ministério da Agricultura, Pecuária e Abastecimento - MAPA. Projeções do Agronegócio: Brasil 2014/2015 a 2024/2025, projeções de longo prazo. Brasília, DF: MAPA, 2015.

BRASIL. Ministério do Desenvolvimento da Indústria e do Comércio MDIC. Estatísticas de Comércio Exterior. [s.d.]. Disponível em: http://www.mdic.gov.br/comercio-exterior/estatisticas-de-comercio-exterior

CARMO, R. L.; OJIMA, A. L. R. O.; OJIMA, R.; NASCIMENTO, T. T. Água virtual, escassez e gestão: o Brasil como grande exportador de água. Ambiente \& Sociedade, Campinas, SP, v. 10, n. 2, P. 83-96, 2007. 
DUARTE, R.; YANG, H. Input-output and water: introduction to the special issue. Economic Systems Research, v. 23, n. 4, p. 341-51, out. 2011.

FAO. Water at a glance. The re-lationship between water, agriculture, food security and poverty. 2007. Disponível em: http://www.fao.org/3/ap505e/ap505e.pdf

HIRSCHMAN, A. The strategy of economic development. New Haven, Connecticut, EUA: Yale University Press, 1958. (Cap. 6).

HOEKSTRA, A. Y.; HUNG, P. Q. Virtual water trade: a quantification of virtual water flows between nations in relation to international crop trade. Value of Water Research Report Series $n$. 11. Delft, The Netherlands: IHE, 2002. Disponível em: https://waterfootprint.org/media/downloads/Report11_1.pdf.

HOEKSTRA, A. Y. Sustainable, efficient, and equitable water use: the three pillars under wise freshwater allocation. Wiley Periodicals, 2013. Disponível em: https://waterfootprint.org/media/downloads/Hoekstra2013-Sustainable-efficient-equitable-water-use.pdf

HOEKSTRA, A. Y. et al. Manual de avaliação da pegada hídrica. Estabelecendo o padrão global. Tradução Solução Supernova. Revisão da tradução Maria Cláudia Paroni. 2011. Disponível em: http://ayhoekstra. nl/pubs/Hoekstra-et-al-2013-ManualDeAvaliacaoDaPegadaHidrica.pdf

IBGE. Produção Agrícola Municipal - PAM. 2003-2015. Rio de Janeiro: IBGE, 2016.

IBGE. Produção Agrícola Municipal - PAM. 2002-2012. Rio de Janeiro: IBGE, 2013.

IMASUL. Gestão ambiental em Mato Grosso do Sul: conceitos e práticas. Eliane Crisóstomo Dias Ribeiro de Barros e Eliane Maria Garcia (Org.). Dourados, MS: Editora UEMS, 2014.

INSTITUTO BRASILEIRO DE FLORESTAS. Bioma Mata Atlântica. Brasília, DF, 2016. Disponível em: http:// www.ibflorestas.org.br/bioma-mata-atlantica.html.

MATO GROSSO DO SUL. Secretaria de Estado de Meio Ambiente e Desenvolvimento Econômico- SEMADE. Perfil Estatístico de Mato Grosso do Sul 2015: ano base: 2014. Campo Grande, MS: SEMADE, 2015.

MATO GROSSO DO SUL. Secretaria de Estado de Meio Ambiente, do Planejamento, da Ciência e Tecnologia e Instituto de Meio Ambiente de Mato Grosso do Sul- SEMAC. Plano estadual de recursos hídricos de Mato Grosso do Sul. Campo Grande, MS: Editora UEMS, 2010.

MEKONNEN, M. M.; HOEKSTRA, A. Y. The green, blue and grey water footprint of crops and derived crop products. Hydrology and Earth System Sciences, n. 15, 2011. Disponível em: https://waterfootprint.org/ media/downloads/Mekonnen-Hoekstra-2011-WaterFootprintCrops_2.pdf

RASMUSSEN, P. N. Studies in intersectorial relations. Amsterdã, North Holland: [s.n.], 1956. (Cap. 8).

WIEDMANN, T.; LENZEN, M.; TURNER, K.; BARRETT, J. Examining the global environmental impact of regional consumption activities - Part 2: review of input-output models for the assessment of environmental impacts embodied in trade. Ecological Economics, v. 61, n. 1, p. 15-26, fev. 2007. 


\section{Sobre os autores:}

Adriana Kirchof de Brum: Doutorado em Economia pela Universidade Federal do Rio Grande do Sul (UFSM). Mestrado em Economia pela Universidade Federal de Santa Catarina (UFSC). Graduação em Ciências Econômicas pela UFSM. Professora e pesquisadora da Universidade Federal da Grande Dourados (UFGD), atuando principalmente nos seguintes temas: políticas públicas, desenvolvimento regional, economia brasileira e economia institucional. E-mail: adrianabrum@ufgd.edu.br

Daniel Massen Frainer: Doutorado em Economia pela Universidade Federal do Rio Grande do Sul (UFRGS). Mestrado em Engenharia de Produção pela Universidade Federal de Santa Catarina (UFSC). Graduação em Ciências Econômicas pela Universidade Federal de Santa Maria (UFSM). Tem experiência na área de Economia, com ênfase em Métodos e Modelos Matemáticos, Econométricos e Estatísticos, atuando principalmente nos seguintes temas: Mato Grosso do Sul, Desenvolvimento Regional, Economia Industrial, Mercado de Trabalho e Meio Ambiente. Atualmente desenvolvendo projetos relacionados com o tema de Matriz de Insumo-Produto Regional. E-mail: danielfrainer@gmail.com

Celso Correia Souza: Doutorado em Engenharia Elétrica e mestrado em Matemática Aplicada pela Universidade Estadual de Campinas (UNICAMP). Graduação em Matemática pela Faculdade de Filosofia Ciências e Letras de Penápolis. Professor aposentado pela Universidade Federal de Mato Grosso do Sul (UFMS), Campus de Três Lagoas, MS. Atualmente, é professor doutor da Universidade Anhanguera Uniderp, Campus de Campo Grande, MS, no Curso de Matemática e nos Mestrados em Meio Ambiente e Desenvolvimento Regional, Produção e Gestão Agroiondustrial e no Doutorado em Meio Ambiente e Desenvolvimento Regional. Tem experiência na área de Probabilidade e Estatística, com ênfase em Probabilidade e Estatística Aplicadas, Otimização e Pesquisa Operacional e Controle Automático de Sistemas. É pesquisador da Fundação Manoel de Barros (FMB) e do Núcleo de Estudos e Pesquisas Econômicas e Sociais (NEPES). E-mail: csouza939@gmail.com

José Francisco dos Reis Neto: Doutor em Administração e Economia com ênfase em Marketing pela Universidad de Salamanca, Espanha. Mestre em Administração pela Universidade Federal do Rio Grande do Sul (UFRGS). Engenheiro Eletricista pela Universidade Estadual Paulista Júlio de Mesquita Filho (UNESP). Professor na Uniderp-Anhanguera. Pesquisador do Núcleo de Estudos e Pesquisas Econômicas e Sociais (NEPES). Tem experiência na área de Administração, com ênfase em Organizações e Marketing, atuando principalmente nos seguintes temas: marketing, estratégia e inovação da micro e pequena empresa, avaliação da opinião pública, desempenho do comércio varejista, cálculo e evolução da inflação campo-grandense. E-mail: jfreisneto@terra.com.br 
